\title{
The Accuracy of Digital Radiography for Diagnosis of Fishbone Foreign Bodies in the Throat
}

\author{
Pornthep Kasemsiri ${ }^{1}$ Kanokkan Mahawerawat ${ }^{1}$ Teeraporn Ratanaanekchai ${ }^{1}$ Warinthorn Puttarak ${ }^{2}$ \\ Waranon Munkong ${ }^{2}$
}

${ }^{1}$ Department of Otorhinolaryngology, Faculty of Medicine, Khon Kaen University, Khon Kaen, Thailand

2 Department of Radiology, Faculty of Medicine, Khon Kaen University, Khon Kaen, Thailand

Address for correspondence Pornthep Kasemsiri, Department of Otorhinolaryngology, Faculty of Medicine, Khon Kaen University, Khon Kaen 40002, Thailand (e-mail: Pkcolumbus99@gmail.com).

Int Arch Otorhinolaryngol 2017;21:255-258.

\begin{abstract}
Introduction Some patients with a fishbone as a foreign body of difficult diagnosis may require further investigations. Generally, radiography is used as the first choice for finding the fishbone.

Objective The objective of this study is to determine the accuracy of digital radiography for diagnosis of fishbone foreign body in the throat

Methods This descriptive experimental study design has three phases. In the first phase, we assessed subject contrast and visibility of fishbone on a homogeneous background; as for the second phase, we evaluated the embedded fishbone in the fresh cadaver's throat. In the last phase, we studied the accuracy of radiography in diagnosing the fishbone foreign body at any site of the cadaver's throat.

Results The subject contrast of 15 fishbones ranged from 0.94 to 0.99 . All types of fishbone were obvious in the first phase, whereas, in the second phase, visibility of fishbone was varied. The subject contrast and diameter of fishbone did not show statistically significant correlation with visibility ( $p=0.09$ and $p=0.24$, respectively). In the third phase, embedded fishbone in the base of tongue was detected with the

Keywords

- fishbone

- foreign body

- radiography

- sensitivity

- specificity highest accuracy (sensitivity of $1.00(95 \% \mathrm{Cl}: 0.44-1.00)$ and specificity of $0.92(95 \% \mathrm{Cl}$ : 0.65-0.99)); whereas, the tonsil was of difficult interpretation with poorest diagnostic value (sensitivity of 0.00 ( $95 \% \mathrm{Cl}: 0.00-0.56$ ) and specificity of 1.00 (95\% Cl: $0.76-1.00)$ ). Conclusion The digital radiography provides the highest accuracy and benefit to the diagnosis of a fishbone foreign body at the base of the tongue; whereas, the tonsil was of difficult interpretation.
\end{abstract}

\section{Introduction}

Foreign body in upper aerodigestive tract is an important clinical problem. There may be mild to serious complications such as tender or irritation of pharynx, infection, abscess, esophageal perforation, mediastinitis, and death. Fishbone is one of the most common foreign bodies in the upper aerodigestive tract. ${ }^{1-4}$ The common site for a fishbone impact is the base of the tongue, palatine tonsils, valleculae, and upper esophagus. ${ }^{5}$ Although most cases can be diagnosed by physical examination, some difficult-to-diagnose cases may need investigations including radiography, barium swallowing, computed tomography (CT), and endoscopy. Plain radiography is the first investigation for diagnosis fishbone foreign body due to non-invasive technique. In the past, plain radiography allowed poor visualization of a fishbone foreign body received

June 28, 2016

accepted

November 3, 2016

published online

January 4, 2017
DOI https://doi.org/

10.1055/s-0036-1597811. ISSN 1809-9777.
Copyright $\odot 2017$ by Thieme Revinter

Publicações Ltda, Rio de Janeiro, Brazil
License terms

(c) (1) $\ominus$ (요 
in the soft tissue comparing with a CT scan ${ }^{4,6}$ or endoscopy. Recently, radiography has developed with novel techniques and advanced digital technology. It yields better visualization and is more precise than conventional plain radiography. ${ }^{7}$ Using digital radiography as the diagnostic tool for detecting fishbone foreign body in the throat may help to decrease unnecessary endoscopy and CT scan.

Several studies ${ }^{3,4,8-10}$ reported varied radio-opacity of fishbones, which depend on numerous factors including the size of the bone, calcium content, and the salinity of the water in which the fish grow. ${ }^{3,5}$ Although the radio-opacity of the fishbone is varied, it is not significantly different between fish that is uncooked, roasted, or simmered in a stock. ${ }^{4}$ Therefore, we designed the embedded uncooked fishbone in the throat of the fresh human cadaver to assess the accuracy of digital radiography for diagnosing a fishbone foreign body.

\section{Methods}

We included in our study 15 commonly eaten species of fish in Southeast Asia (-Fig. 1). We designed the study into three phases to assess the value of radiography in the diagnosis of fishbone foreign bodies in the throat. The study took place during September 2012 to August 2013.

In the first phase, we evaluated subject contrast of fishbones for each species with the ratio between pixel value of fishbone (the value of X-ray can pass through the object) and background pixel value (the value of $\mathrm{X}$-ray can pass through the area around the fishbone). Backgrounds in each area must be similar in pixel value, varying no more than $10 \%$. In this study, the background pixel value was different from $0.58 \%$. The mean of background pixel value was 3690.79 with a standard deviation of 21.32 . Additionally, two radiologists assessed the visibility and classified participants into three groups: invisible group, unclear group, and obvious group. If the two radiologists' interpretations were different, they had to reach a consensus.

In the second phase, we applied the lateral soft tissue neck digital radiograph to evaluate the embedded fishbone foreign body of each species in the fresh human cadaver's throats. We cut all of the fishbones to $2 \mathrm{~cm}$ in length and recorded the diameter of bones by caliper (scale $0.1 \mathrm{~mm}$ ). After placing each species of the fishbone on the vallecula of the fresh human cadaver, we took lateral neck digital radiograph with $60 \mathrm{kvP}$, $100 \mathrm{~mA}, 5 \mathrm{mAs}$ by general radiography system: radnet $80 /$ radnext 50 Hitachi and digital radiography "Fuji film DR" FDR D-EVO (DR-ID600) (-Fig. 2). In addition, we designed one radiograph without fishbone as a controlled trial. The visibility of fishbone was interpreted in the same way as the first phase.

In the third phase, the aim was to study the accuracy of the radiography to diagnose the fishbone foreign body in any site of the throat including tonsil, base of tongue, vallecula, and upper esophagus. Regarding varying ossification of the laryngeal cartilage, we used only one fresh human cadaver; however, we were concerned with multiple embedding of all of fishbones in one cadaver that could affect the radiologists' interpretations due to the phenomenon of air in soft tissue as an artifact around the fishbone. Therefore, we selected one fishbone in each of the three visibility group and cut to $2 \mathrm{~cm}$ in length and in a similar diameter. Each species of fishbones was embedded into the tonsil, base of tongue, vallecula, and upper esophagus. We applied lateral neck digital radiograph. We created controlled radiograph

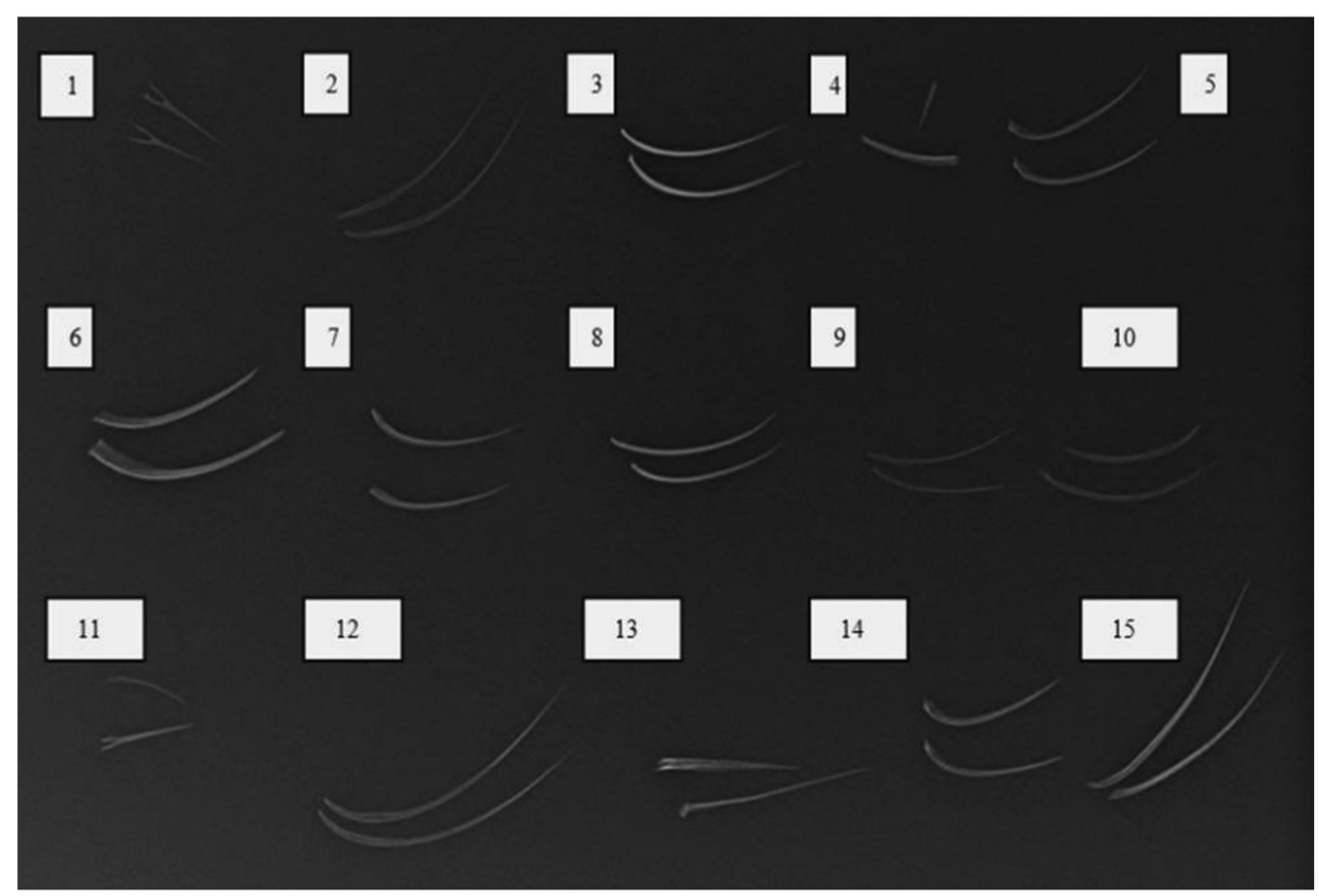

Fig. 1 Fifteen species of fishbone included: (1) Walking catfish; (2) Short-body mackerel; (3) White snapper; (4) King mackerel; (5) Jullien's Golden-price carp; (6) Silver barb; (7) Threadfin bream; (8) Striped snakehead; (9) Yellow stripe trevally; (10) Black pomfret; (11) Snake skin gourami; (12) Nile tilapia (13); Striped catfish; (14) Mullet; (15) Red tilapia. 


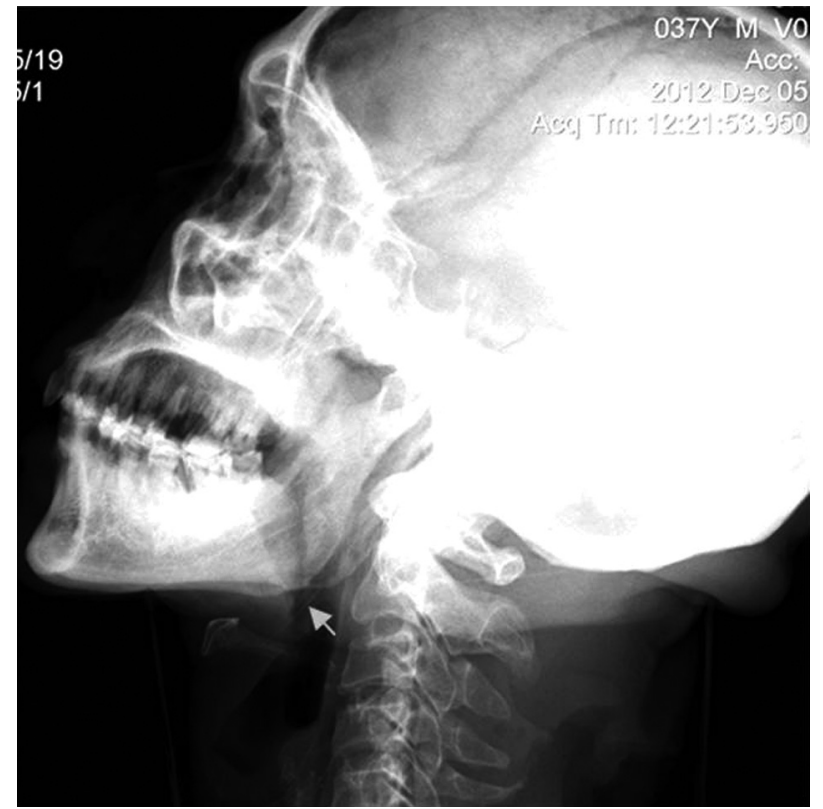

Fig. 2 The arrow indicates the embedded fishbone in fresh human cadaver's valleculae. without fishbone for the three visibility groups. The same two radiologists interpreted the radiographs, who noted whether the fishbone was present or absent in the cadaver's throat and described the site of where the fishbone presented. The local ethics committee approved this study (HE551282).

\section{Results}

-Table 1 shows the subject contrasts of fifteen species of fishbone. Regarding visibility, all species of fishbone were obvious in the first phase; whereas, visibility of fishbone in the second phase (embedded fishbone in the cadaver' throat) was varied. The radiologists interpreted the obvious visible group as $46.67 \%$, the unclear group was $20 \%$, and the invisible group was 33.33\% (-Table 1). We analyzed the correlations of visibility factors including subject contrast and diameter of fishbone with the Spearman's rank Correlation Coefficient which showed non-significant correlation $(p=0.09$ and $p=0.24$, respectively). Furthermore, the analysis of variance between visibility in each group and subject contrast was also not statistically significant ( $p=0.25$ ) ( - Table 2 ). In the third phase, we selected the King Mackerel, Striped Snakehead, and

Table 1 Subject contrast and visibility of fifteen species of fishbone

\begin{tabular}{|c|c|c|c|c|c|c|}
\hline \multirow[t]{3}{*}{ Species of fishbone } & \multicolumn{5}{|l|}{ Phase 1} & \multirow{3}{*}{$\begin{array}{l}\text { Phase } 2 \\
\text { Visibility }\end{array}$} \\
\hline & \multirow{2}{*}{$\begin{array}{l}\text { Diameter } \\
\text { of FB }(\mathrm{mm})\end{array}$} & \multicolumn{2}{|c|}{ Mean of pixel value } & \multirow[t]{2}{*}{ Subject contrast } & \multirow[t]{2}{*}{ Visibility } & \\
\hline & & FB (US) & BG (US) & & & \\
\hline $\begin{array}{l}\text { Black Pomfret } \\
\text { (P.niger) }\end{array}$ & 0.9 & 3653.86 & 3705.85 & 0.99 & 2 & 2 \\
\hline $\begin{array}{l}\text { Yellowstripe Trevally } \\
\text { (S. leptolepis) }\end{array}$ & 0.9 & 3646.50 & 3704.77 & 0.98 & 2 & 1 \\
\hline $\begin{array}{l}\text { Short-bodied Mackerel } \\
\text { (R. brachysoma) }\end{array}$ & 1.3 & 3641.68 & 3694.38 & 0.99 & 2 & 0 \\
\hline $\begin{array}{l}\text { King Mackerel } \\
\text { (S. commerson) }\end{array}$ & 1.8 & 3636.22 & 3711.80 & 0.98 & 2 & $0^{*}$ \\
\hline $\begin{array}{l}\text { Jullien's Golden-Price Carp } \\
(P . \text { jullieni })\end{array}$ & 1.5 & 3624.26 & 3713.50 & 0.98 & 2 & 2 \\
\hline $\begin{array}{l}\text { Walking catfish } \\
\text { (Clarias spp.) }\end{array}$ & 0.8 & 3600.91 & 3679.74 & 0.98 & 2 & 1 \\
\hline $\begin{array}{l}\text { Snake Skin Gourami } \\
\text { (T. pectoralis) }\end{array}$ & 0.8 & 3589.61 & 3643.21 & 0.99 & 2 & 0 \\
\hline $\begin{array}{l}\text { Mullet } \\
\text { (Mugilidae) }\end{array}$ & 1 & 3580.75 & 3681.44 & 0.97 & 2 & 0 \\
\hline $\begin{array}{l}\text { Threadfin Bream } \\
\text { (Nemipterus spp.) }\end{array}$ & 1.3 & 3568.00 & 3681.78 & 0.97 & 2 & 2 \\
\hline $\begin{array}{l}\text { Nile Tilapia } \\
\text { (O. niloticus) }\end{array}$ & 1 & 3565.09 & 3664.08 & 0.97 & 2 & 0 \\
\hline $\begin{array}{l}\text { Striped Catfish } \\
(P . \text { sutchi })\end{array}$ & 1 & 3554.20 & 3678.40 & 0.97 & 2 & 2 \\
\hline $\begin{array}{l}\text { Silver Barb } \\
\text { (B. goinonotus) }\end{array}$ & 1.5 & 3543.37 & 3677.45 & 0.96 & 2 & $2^{*}$ \\
\hline $\begin{array}{l}\text { Red Tilapia } \\
\text { (O. niloticus) }\end{array}$ & 1.9 & 3521.59 & 3691.50 & 0.95 & 2 & 2 \\
\hline $\begin{array}{l}\text { Striped snakehead } \\
\text { (C. striata) }\end{array}$ & 1.5 & 3517.81 & 3716.51 & 0.95 & 2 & $1^{*}$ \\
\hline $\begin{array}{l}\text { White Snapper } \\
\text { (L. calcarifer) }\end{array}$ & 1.2 & 3490.95 & 3717.40 & 0.94 & 2 & 2 \\
\hline
\end{tabular}

Abbreviation: BG, background; FB, fishbone.

${ }^{*}$ Fishbones represent each group of visibility ( $0=$ invisibility group, $1=$ unclear visibility group, 2 = obvious visibility group). 
Table 2 Correlation of the visibility factors

\begin{tabular}{|l|l|}
\hline Spearman's rank Correlation Coefficient & $p$ Value \\
\hline Visibility versus Subject contrast & 0.09 \\
\hline Visibility versus Diameter of fishbones & 0.24 \\
\hline Analysis of variance & - \\
\hline Visibility in each group versus Subject contrast & 0.25 \\
\hline
\end{tabular}

Silver Barb as the agents of the three visibility groups: the invisible, unclear, and obvious groups, respectively. Overall, the radiologists correctly interpreted ten of fifteen radiographs (66.67\%, 95\%CI: 38.38-88.17). Regarding the precision of digital radiograph, the fishbone foreign body at the base of tongue resulted in the highest accuracy; whereas, the tonsil was of difficult interpretation with the poorest diagnostic value (-Table 3 ).

\section{Discussion}

In the past, plain radiograph was used to detect the fishbone as a foreign body in the throat, but the quality of visualization was poor. Since then, new advanced digital technology has been developed that improves visualization. The accuracy of the radiograph was reported but it was of varying value; therefore, we designed the study into three phases to investigate diagnostic value. In the first phase, we placed the fishbone on the homogenous background. All of them can be identified with high subject contrast of 0.94-0.99. Although the fishbone has high radio-opacity, it was difficult to identify when embedded in the throat in the second phase. We observed that the two radiologists' visibility decreased in the second phase. The fishbones were classified into three groups: obvious, unclear, and invisible group. Most of them fell into the obvious group (46.67\%), whereas the unclear and invisible group represented $20 \%$ and $33.33 \%$, respectively. The decreased visibility may be a consequence of many factors, including site and air around of the embedded fishbone, ${ }^{9}$ diameter ${ }^{4}$ and direction of fishbone, ${ }^{11}$ and human laryngeal ossification. ${ }^{9}$ For identifying the correlation of visibility factors ( - Table 2 ), we designed the fishbone in the same length and placed it on a fresh human cadaver's valleculae. We aimed to eliminate the confounding factors including site, direction, and laryngeal ossification. The result showed the correlations of visibility factor including subject contrast and diameter of fishbone that were not statistically significant $(p>0.05)$. However, the limitation of this study is using only one cadaver due to concerns with varying laryngeal ossification.

Regarding the site of the embedded fishbone in the throat, the base of the tongue produced the highest accuracy, whereas, the tonsil was of difficult interpretation with the poorest diagnostic value. These results may be a result of the angle of mandible, obscuring the tonsil and causing greater difficulty in its interpretation than other sites. However, embedding the fishbone in the cadaver in the third phase may present the air around fishbone; therefore, we embedded the fishbone less than 8 times for reducing this confounding factor.
Table 3 Diagnostic value of radiographs for diagnosis fishbone foreign body in different site of throat

\begin{tabular}{|l|l|l|}
\hline Site & $\begin{array}{l}\text { Sensitivity } \\
(\mathbf{9 5 \%} \mathrm{Cl})\end{array}$ & $\begin{array}{l}\text { Specificity } \\
(95 \% \mathrm{Cl})\end{array}$ \\
\hline Base of tongue & $1.00(0.44-1.00)$ & $0.92(0.65-0.99)$ \\
\hline Valleculae & $0.67(0.21-0.94)$ & $1.00(0.76-1.00)$ \\
\hline Upper esophagus & $0.67(0.21-0.94)$ & $0.83(0.55-0.95)$ \\
\hline Tonsil & $0.00(0.00-0.56)$ & $1.00(0.76-1.00)$ \\
\hline
\end{tabular}

Overall, our study yielded $66.67 \%$ accuracy (95\%CI: $38.38-$ 88.17), which is similar to previous studies. Therefore, the radiograph is one of the non-invasive investigations that help to diagnose fishbone foreign bodies in the throat, especially at the base of tongue, valleculae, and upper esophagus. It does, however, have poor accuracy for fishbones embedded at the tonsil, although a foreign body in this area is easily detected with careful physical examination.

\section{Conclusions}

All species of fishbone have high radio-opacity but each one has different visibility when embedded in the throat due to the existence of many confounding factors. However, digital radiography provides high accuracy and great benefit in the diagnosis of fishbone foreign bodies at the base of the tongue, vallecular, and upper esophagus.

\section{References}

1 Nandi P, Ong GB. Foreign body in the oesophagus: review of 2394 cases. Br J Surg 1978;65(1):5-9

2 Atchariyasathian V, Tanormkiat V. Detection of foreign bodies in the digestive tract,using rigid esophagoscopy and the plain film soft tissue neck X-ray. Songkla Med J 2003;21(1):45-51

3 Kumar M, Joseph G, Kumar S, Clayton M. Fishbone as a foreign body. J Laryngol Otol 2003;117(7):568-569

4 Lue AJ, Fang WD, Manolidis S. Use of plain radiography and computed tomography to identify fishbone foreign bodies. Otolaryngol Head Neck Surg 2000;123(4):435-438

5 Jackson CL. Foreign bodies in air and food passages. Postgrad Med 1948;4(4):281-290

6 Palme CE, Lowinger D, Petersen AJ. Fishbones at the cricopharyngeus: a comparison of plain-film radiology and computed tomography. Laryngoscope 1999;109(12):1955-1958

7 Davies WR, Bate PJ. Relative radio-opacity of commonly consumed fish species in South East Queensland on lateral neck X-ray: an ovine model. Med J Aust 2009;191(11-12):677-680

8 Abdullah BJ, Kaur H, Ng KH. An in vitro study comparing two different film-screen combinations in the detection of impacted fishbones. Br J Radiol 1998;71(849):930-933

9 Ell SR, Sprigg A, Parker AJ. A multi-observer study examining the radiographic visibility of fishbone foreign bodies. J R Soc Med 1996;89(1):31-34

10 Ell SR, Sprigg A. The radio-opacity of fishbones-species variation. Clin Radiol 1991;44(2):104-107

11 Hone SW, Fenton J, Clarke E, Hamilton S, McShane D. The radioopacity of fishbones: a cadaveric study. Clin Otolaryngol Allied Sci 1995;20(3):234-235 